Sharif University of Technology
Scientia Iranica
SCIENTIA
IRAN Transactions B: Mechanical Engineering
www.scientiairanica.com

\title{
Dynamic behaviour of $\beta$-Ti-15333 in ultrasonically assisted turning: Experimental and numerical analysis
}

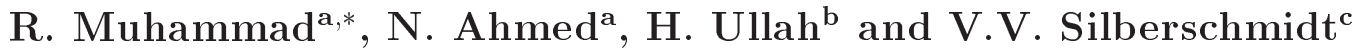 \\ a. Department of Mechanical Engineering, CECOS University of IT \& Emerging Sciences, Peshawar, KP, Pakistan. \\ b. CESAT, H 11/4, Islamabad, Pakistan. \\ c. School of Mechanical \& Manufacturing Engineering, Loughborough University, Loughborough, UK.
}

Received 21 January 2016; received in revised form 2 August 2016; accepted 29 October 2016

\section{KEYWORDS \\ Ti-alloys; \\ SHPB; \\ Turning; \\ Machining; \\ Finite-element.}

\begin{abstract}
The enhanced strength, fatigue life, and corrosion resistance properties of Tialloys have attracted many industries for their utilization in various components exposed to extreme operating conditions. The machining of these alloys using conventional machining techniques is one of the main challenges in its wide application in many components, and there is an obvious demand to analyse the materials' response to these alloys in machining processes by developing simulation-based models. The materials' behaviour used in simulation of machining processes is usually determined by means of Split-HopkinsonPressure-Bar (SHPB) setup. A 3D thermo-mechanically coupled Finite-Element (FE) model of SHPB is developed in the current work to analyse materials response of $\beta$-Ti- 15333 at the selected temperature, strain rate, and strain. The obtained materials' response to the tested alloys is used in 3D thermo-mechanically coupled FE model of ultrasonically assisted turning and conventional turning at various tested cutting conditions. The developed FE model is used for parametric analysis of $\beta$-Ti-15333 machining, and the obtained FE results are in good agreement with experimental results.

(C) 2017 Sharif University of Technology. All rights reserved.
\end{abstract}

\section{Introduction}

The machinability of $\beta$-Ti-alloys is characterised by high level of cutting forces and extreme temperature at the process zone in machining processes due to its low thermal-conductivity and high-strength [1-4]. The produced plastic deformation in $\beta$-Ti-alloys in Ultrasonically Assisted Turning (UAT) and Conventional Turning (CT) results in the high level of temperature, strain rate, and strain in the process zone. The level of strain rate in moderate speed machining of hard-to-cut alloys usually reaches $10^{5} \mathrm{~s}^{-1}$ to achieve

*. Corresponding author.

E-mail address: R.Muhammad@cecos.edu.pk (R.

Muhammad)

doi: $10.24200 /$ sci. 2017.4312 material separation. The accurate incorporation of these high level strain rate and temperature-dependent behaviours of material used in Finite-Element (FE) simulation is the vital and critical step in numerical analysis of machining processes [5,6]. Among many, Split-Hopkinson-Pressure-Bar (SHPB) setup is one of the commonly used experimental techniques to determine materials' response at elevated strain and strainrate levels. The method is useful for the prediction of materials' response at the strain rate levels, ranging from $10^{1}$ to $10^{4} \mathrm{~s}^{-1}$. However, the strain rate level in machining process at the primary and secondary deformation zones surpasses the achieved levels in SHPB tests and, therefore, cannot be used in the FE simulation of machining processes.

The data obtained from SHPB tests are based on some basic approximations, containing the practice of uniformity of strain and stress used in 1D-theory 
of elastic wave spread, evenness of strain, and stress distribution in the direction of the axis of the wave propagation and the ignoring of the frictional effect. The details of the studied effects of these parameters on the obtained results of SHPB tests are available elsewhere [7]. These assumptions are critically assessed by various researchers worldwide, both numerically and experimentally, and the advantages and disadvantages of SHPB tests are highlighted [8-11].

In the past, researchers used Johnson-Cook (JC) [12] model, which is a curve fitting technique to predict materials response at higher strain rate, strain and temperature used in FE simulation of machining processes [10,13-17]. The model has the capability to represent materials' response accurately in machining operations and produce precise results in FE simulation with the achieved experimentations. However, there are other materials' models also available in the literature that need to be tested in the FE simulation of machining processes. In the current study, a piecewise linear material model is used to incorporate the materials response at these higher strain rates, temperatures, and strains. The main limitation of the piecewise linear material model is that it needs tested material response at $10^{5} \mathrm{~s}^{-1}$ for machining simulations, which is not the case in the current study. Therefore, there is a need to use advanced FE tools to predict materials' response at those high strain rate levels, and then used it in FE simulations of machining processes.

Hence, the data obtained from experimentations of the SPHB tests were verified with a developed 3D FE model of SPHB setup at the studied levels of strain, temperature, and strain rates. The developed model was also used to investigate the deformation mechanism of $\beta$-Ti-15333 alloy at the tested loads of various combinations of temperatures and strain rates. Later on, the model was used to extrapolate the achieved materials' response from SHPB tests to the required level of strain rate reached in machining processes to accurately represent materials' response in $\mathrm{FE}$ simulation of $\beta$-Ti15333.

Moreover, a coupled 3D thermo-mechanically FE model of UAT and CT was established to carry out parametric study of $\beta$-Ti-15333 at various cutting conditions. The developed model was examined for the level of cutting forces, stresses, and temperature induced in the process zone at various tested conditions.

\section{SPHB tests}

The SPHB setup used in the current work consists of two managing steel rods: transmitted bar and incident bar, each with diameter lengths of $1200 \mathrm{~mm}$ and $21.77 \mathrm{~mm}$, as shown in Figure 1. A striker rod having the same diameter as that of incident rod and length of $200 \mathrm{~mm}$ is used as a source to apply load to the incident bar from the pressurized cylinder. $\beta$-Ti-15333 sample used in the SHPB tests with a diameter of $8 \mathrm{~mm}$ and $6 \mathrm{~mm}$ length is mounted between the incident and transmitted rods. The resistance strain gauges are fixed on the incident and transmitted rods to measure the response of $\beta$-Ti-15333 due to the applied load. The load is applied to the incident rods with a striker rod at the certain level of strain rate and is spread toward the specimen (see Figure 1). The propagated pulse from the incident rod is divided into two streams, once reached the mounted sample. A part of pulse travels through the sample and reaches the transmitted rod because of plastic deformation, and the resistance strain gauges attached to it record the levels of those stresses. Similarly, an elastic pulse reflected back to the incident rod from $\beta$-Ti-15333 specimen is noted by the mounted strain gauge on it. A $1 \mathrm{D}$-wave propagation theory is applied to define the level of stress, strain rate, and strain in $\beta$-Ti-15333 specimen from the achieved experimental data. The details are given below [18]:

$$
\begin{aligned}
& \varepsilon(T)=-\frac{2 B}{l_{s}} \int_{0}^{t} \varepsilon_{R}(T), \\
& \dot{\varepsilon}(T)=-\frac{2 B}{l_{s}} \varepsilon_{R}(T), \\
& \sigma(T)=\frac{a_{b} E_{b}}{a_{s}} \varepsilon_{T}(T),
\end{aligned}
$$

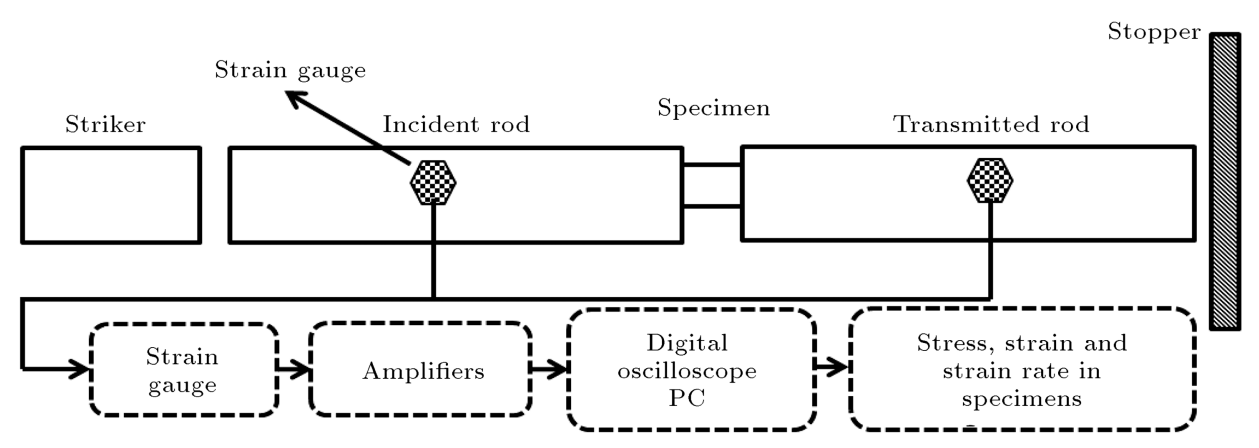

Figure 1. Block diagram of SHPB experimental setup used in the study. 


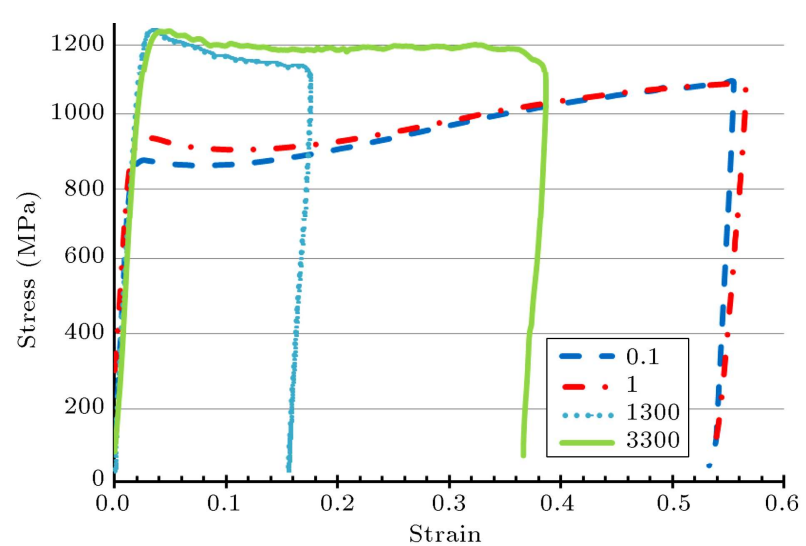

Figure 2. Materials response of $\beta-\mathrm{Ti}-15333$ at studied strain level from SHPB tests [19].

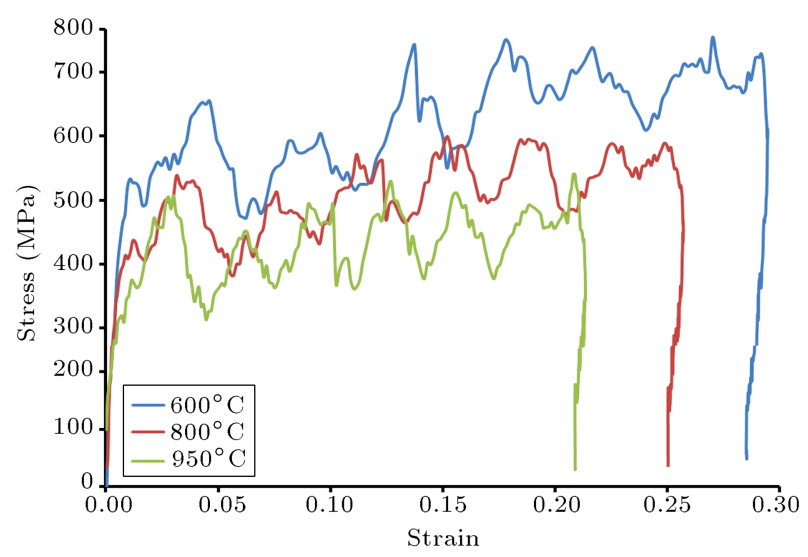

Figure 3. SHPB tests results at various temperatures and $3300 \mathrm{~s}^{-1}$ strain rate [23].

where $B$ is the velocity of elastic wave, $l_{s}$ is the specimen initial length, $\varepsilon_{T}$ and $\varepsilon_{R}$ are the strain pulse levels of transmitted and reflected waves, respectively, $a_{s}$ and $a_{b}$ are $\beta$-Ti-15333 specimen and rods cross-sectional areas, respectively, $E_{b}$ is the elastic-modulus of the rod materials, $\dot{\varepsilon}(T)$ represent the strain rate, $\varepsilon(T)$ is the level of strain, and $\sigma(T)$ represents the level of the resulted stresses.

$\beta$-Ti-15333 specimen was prepared using a wire cut machine to achieve length-to-diameter ratio within the range of 0.5 to 1 . The length-to-diameter ratio of $\beta$-Ti-15333 specimen used in the tests was 0.75 . The tests were conducted at $0.1,1,600,1300$, and $3300 \mathrm{~s}^{-1}$ strain rate levels as shown in Figure 2. Similarly, tests at various temperature levels of $20^{\circ} \mathrm{C}, 600^{\circ} \mathrm{C}$, $800^{\circ} \mathrm{C}$, and $950^{\circ} \mathrm{C}$ were also carried out to achieve $\beta$ Ti-15333 response (see Figure 3) [19]. A decline in the strength of the studied materials was observed at elevated temperature, as expected.

\section{Machining tests}

The conventional lathe machine (Harrison-300) modified to mount the piezo-ceramic transducer on the tool post was used in the current study. A custom-built fixture was fabricated to fix the designed transducer on the lathe machine and cutting inserts were fixed on the free end of the transducer. The developed ultrasonic system at Loughborough University, UK, is an open loop system optimized for vibrational parameters of $8 \mu \mathrm{m}$ amplitude and $20 \mathrm{kHz}$ frequency. The system is also designed in such a way as to carry out both CT and UAT by simply switching on the ultrasonic vibration on the cutting tool. A dynamometer of Kistler type offers the measured level of cutting forces in real time at the studied cutting parameters. The data obtained from the dynamometer were passed through a data acquisition system, and response of the cutting forces was recorded. For thermal analysis of the process zone, a FLIR ThermaCAM ${ }^{\mathrm{TM}}$ SC-3000 system was used to calculate the process-zone temperature in UAT and CT. The thermal camera was calibrated in the lab before conducting the tests on the studied alloys. The data obtained in experimentation were further analysed using the ThermaCAMß QuickView ${ }^{\mathrm{TM}}$ software. Figure 4 shows the experimental setup used for CT and UAT of $\beta$-Ti-15333.

\subsection{Cutting insert and workpiece materials in turning tests}

A $500 \mathrm{~mm}$ length and $60 \mathrm{~mm}$ diameter ingot of $\beta$-Ti15333 was used in UAT and CT tests. $\beta$-Ti-15333 rod was attached to the chuck of the lathe-machine and eccentricity of the work piece was adjusted using a mechanical dial gauge. All tests were conducted in dry-cutting conditions. The cutting inserts used in the experimentation were DNMG150608 manufactured by SECO. The tested cutting conditions in turning experiments are shown in Table 1 and is recommended for $\beta$-Ti-15333 alloy by the funding agency for the current work. Additional details about $\beta$-Ti-15333 alloy can be found elsewhere [20].

\section{FE models}

\subsection{SHPB model}

A 3D FE model for SHPB was developed in MSC MARC-MENTAT as shown in Figure 5 to predict the materials' behaviour at strain rate levels observed in machining processes. The achieved experimental data from the SHPB tests represent $\beta$-Ti-15333 response up

Table 1. Cutting conditions used in the experiments.

\begin{tabular}{lc}
\hline Cutting parameters & Magnitude \\
\hline Depth of cuts & $100-500 \mu \mathrm{m}$ \\
Feed rate & $100 \mu \mathrm{m} / \mathrm{rev}$ \\
Cutting speed & $10-70 \mathrm{~m} / \mathrm{min}$ \\
Lubricant & Dry cutting \\
\hline
\end{tabular}




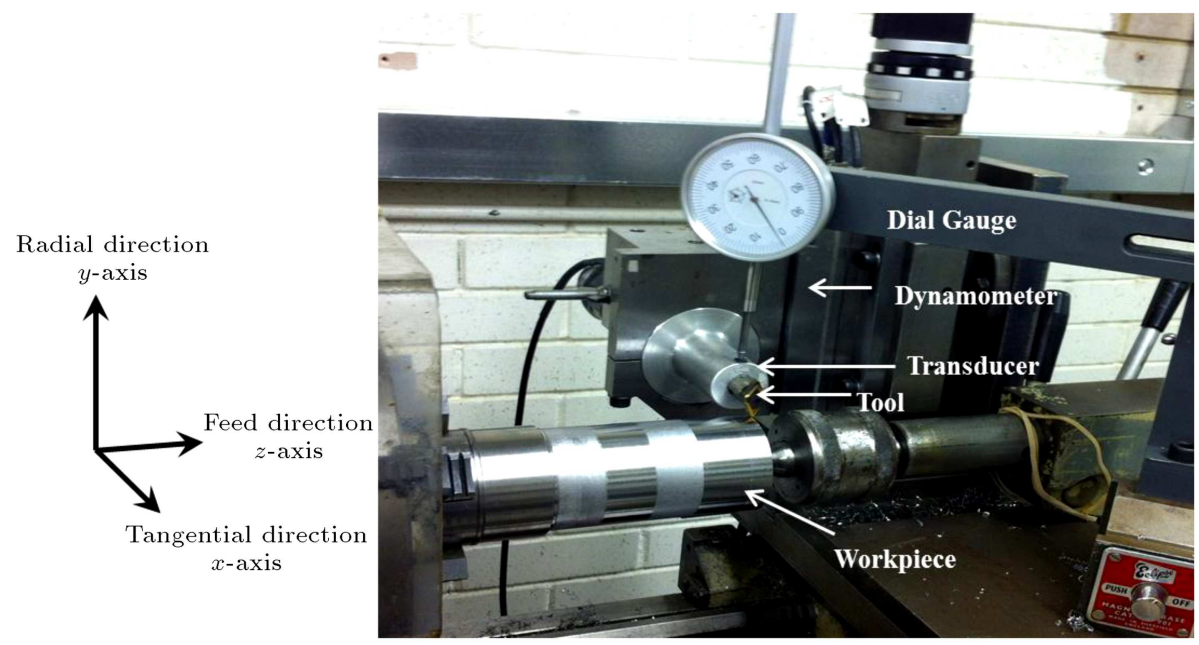

Figure 4. Experimental setup for turning experiments [23].

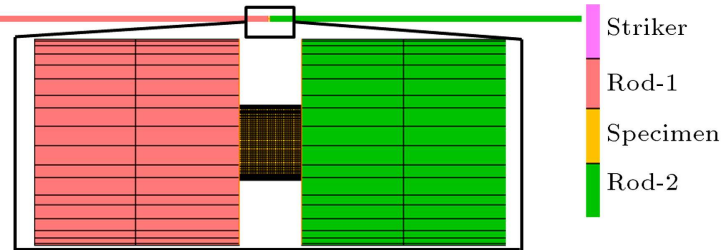

Figure 5. The developed FE model of SHPBT [23].

to a maximum of $3300 \mathrm{~s}^{-1}$ due to the limitation of the setup used. The specimen used in SHPB tests, incident, striker and transmitted rods was modelled using 8-node hexahedral and isoparametric elements available as element type 7 in the MSC MARC library as per the dimension presented in Table 2. The striker and transmitted rods were allowed to move in the direction of the shaft axis, and reflected rod was constrained in this direction to replicate the effect of stopper on it. The materials' properties, available in Table 2, were assigned to SHPB setup bars and the achieved data from SHPB tests were used in the model for $\beta$-Ti-15333 specimen using a piecewise linear materials model (Eq. (4)) with slight modification to eliminate the convergence problems faced in $\mathrm{FE}$ simulations, as shown in Figure 6.

$$
\sigma=\sigma(\varepsilon, \dot{\varepsilon}, T),
$$

where $\sigma$ is the yield stress, $\varepsilon, \dot{\varepsilon}$, and $T$ are the strain, strain rate, and temperature, respectively.

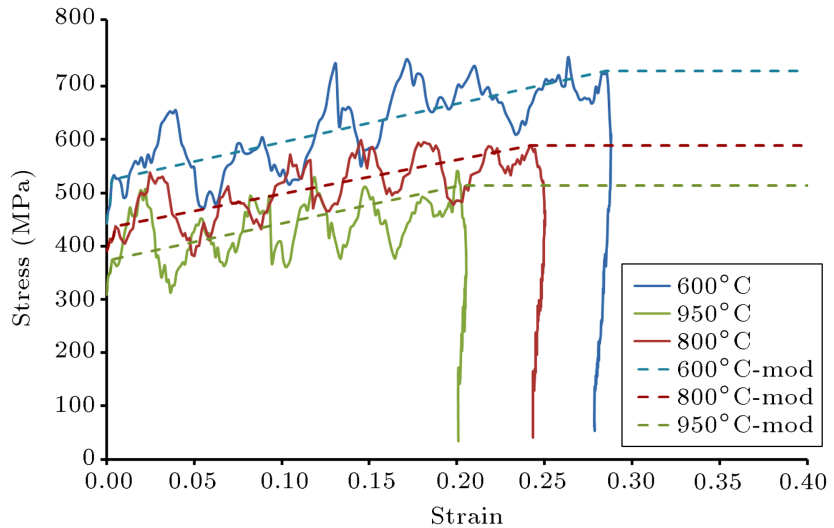

Figure 6. Modification in SHPB data to eliminate variation and convergence problems in $\mathrm{FE}$ simulations.

\subsection{FE modelling of $U A T$ and $C T$}

A 3D FE model of UAT and CT was developed in MSC MARC-MENTAT, as shown in Figure 7. A deformable $\beta$-Ti-15333 workpiece having a width of $1.3 \mathrm{~mm}$, length of $5 \mathrm{~mm}$, and $0.5 \mathrm{~mm}+a_{p}$ height was modelled using 8-node hexahedral elements. The initially used 8-node elements were changed to 5 -node tetrahedron elements using global remeshing technique to elude excessive deformation in the workpiece and chip separation. The cutting insert having $800 \mu \mathrm{m}$ nose radius, $14.5^{\circ}$ rake angle, $25 \mu \mathrm{m}$ cutting edge radius, and $0^{\circ}$ end relief angle was developed in Pro-Engineer and exported

Table 2. Mechanical properties and dimensions of rods/specimen used in the SHPB system.

\begin{tabular}{lcccccc}
\hline & Material & $\begin{array}{c}\text { Length, } \\
\boldsymbol{l}(\mathbf{m m})\end{array}$ & $\begin{array}{c}\text { Diameter, } \\
\boldsymbol{d}(\mathbf{m m})\end{array}$ & $\begin{array}{c}\text { Modulus of } \\
\text { Elasticity } \\
(\mathbf{G P a})\end{array}$ & $\begin{array}{c}\text { Passion's } \\
\text { ratio }\end{array}$ & $\begin{array}{c}\text { Density } \\
\left(\mathbf{k g} / \mathbf{m}^{\mathbf{3}}\right)\end{array}$ \\
\hline Striker rod & Maraging-steel & 200 & 21.77 & 198 & 0.329 & 8470 \\
Bars & Maraging-steel & 1200 & 21.77 & 198 & 0.329 & 8470 \\
Specimen & $\beta$-Ti-15333 & 6 & 8 & 87 & 0.3 & 4900 \\
\hline
\end{tabular}




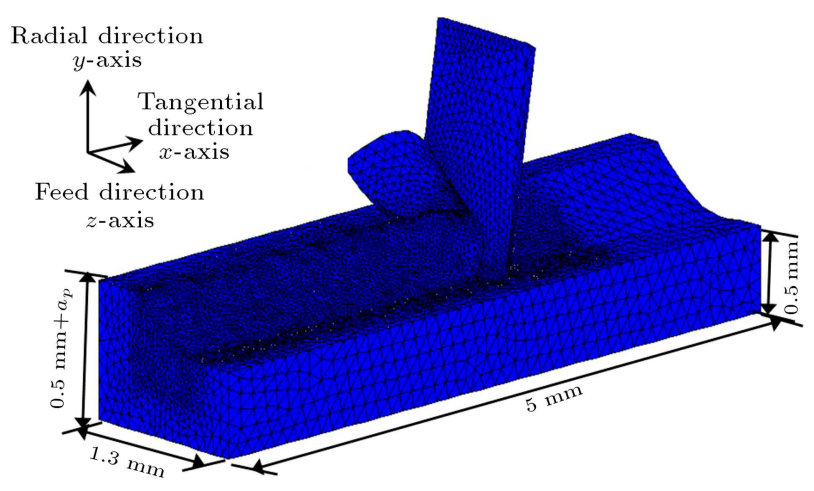

Figure 7. Developed FE model of UAT and CT.

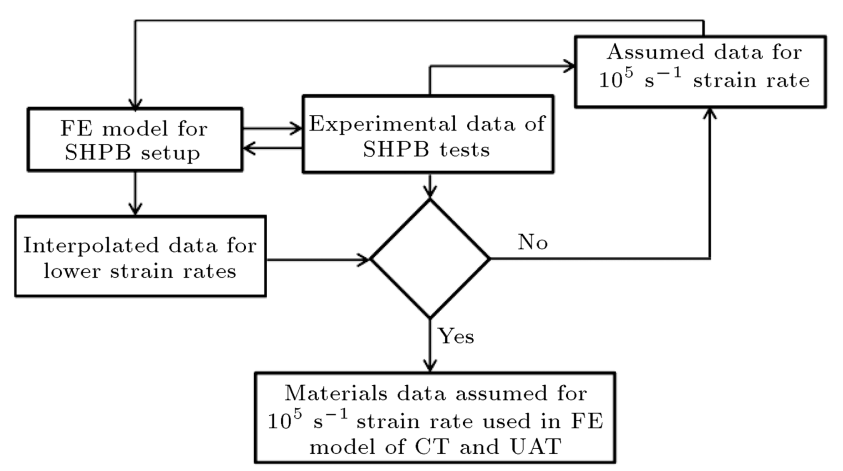

Figure 8. Flow chart explaining the extrapolation of materials response at $10^{5} \mathrm{~s}-1$ strain rate.

later on to MSC MARC-MENTAT. The cutting insert was used as a rigid body allowing heat transfer to the environment and from the process zone. The cutting insert was discretised to 4-node tetrahedral elements having finer mesh close to the cutting edge and coarse mesh in the region not involved in the cutting operation. The cutting velocity was applied to the workpiece materials in $X$-Axis (tangential direction, Figure 7 ). The feed velocity in both CT and UAT was provided for the cutting tool in $Z$-Axis. UFltrasonic vibrations having $20 \mathrm{kHz}$ frequency and $0.008 \mathrm{~mm}$ amplitude were applied to the cutting insert in $X$-Axis to investigate their effect on UAT.

A piecewise linear materials model was implemented to incorporate materials' behaviour into the developed FE model for UAT and CT. The FE model of SHPB setup was used to predict the materials' response at strain rate of $10^{5} \mathrm{~s}^{-1}$ and was incorporated into the FE simulation of UAT and CT. The prediction of materials' response at high strain rate level was achieved using a sequence of operation as explained in Figure 8. The friction phenomenon at the insert-work piece interface was modelled using a modified shear friction model.

$$
\sigma_{f r} \leq-m_{f r} \frac{\bar{\sigma}}{\sqrt{3}} \frac{2}{\pi} \operatorname{sgn}\left(V_{r}\right) \operatorname{artan}\left(\frac{V_{r}}{V_{c r}}\right),
$$

where $V_{r}$ is the chip sliding-velocity, $\sigma_{f r}$ is the frictional-stress, $\bar{\sigma}$ is the level of equivalent stress, $V_{c r}$ is a sliding critical-velocity for sticking activation, $m_{f r}$ represents the coefficient of friction, and $\operatorname{sgn}(x)$ is the signum function.

The chip separation from the workpiece in the FE simulation of UAT and CT was achieved through global remeshing technique, built into the feature of MSC MARC Mentat.

\section{Discussions on results}

\subsection{FE results of $S H P B$}

The developed FE model of SHPB was used to calculate the axial-strain level at the desired point on the bar where the resistance strain gauge was mounted, as shown in Figure 9. A propagation of compressive strain in the incident rod was observed when the striker rod smashed it. A rapid increase of 0.04 in the incident rod at strain level was observed when the striker fully hit it. The level of strain started to decay and reached the lower level of strain at $0.14 \mathrm{~s}$ before the plastic deformation of the specimen was placed between the incident and transmitted rods. The specimen's plastic deformation response in the reflected and transmitted pulses was achieved in incident and transmitted rods, respectively. The model was used for various strain rate levels of deformation of the tested specimen, and reasonably good agreement between the experimental and FE results was accomplished. Figure 10 shows the response of $\beta$-Ti- 15333 both experimentally and numerically at the strain rate level of $3300 \mathrm{~s}^{-1}$.

At the start of the compression of the specimen, inconsistent plastic deformation was observed in the studied $\beta$-Ti-15333. The homogenous state of the stress was achieved at $3 \%$ of strain in the FE results. A total variation of approximately $138 \mathrm{MPa}$ in the axial stress was observed at the initial contact between the incident bar and sample, as shown in Figure 11. Similarly,

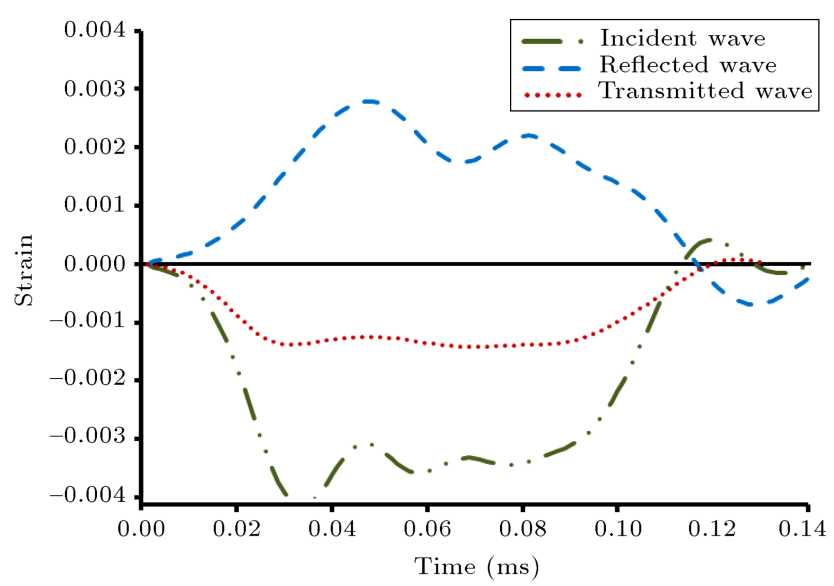

Figure 9. The level of strain calculated in the reflected and incident rods. 


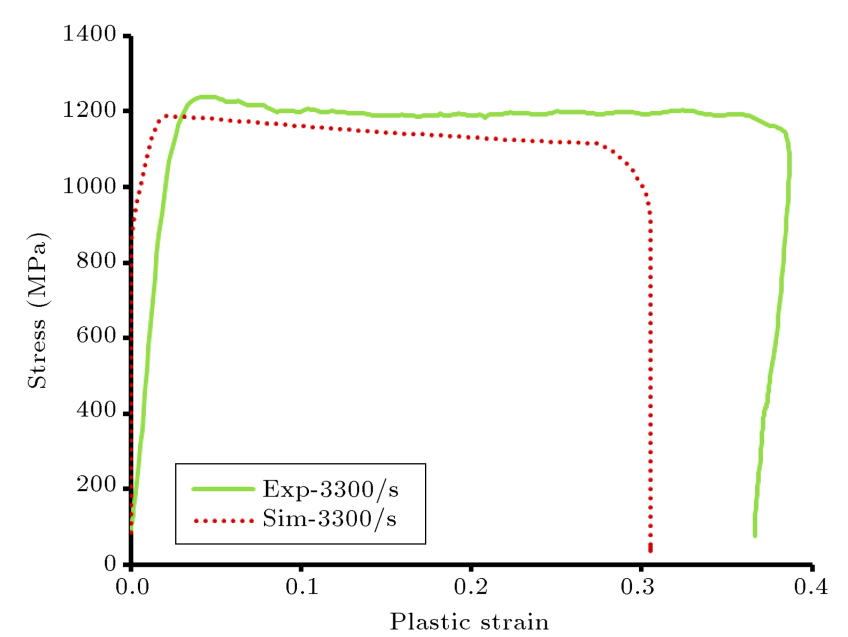

Figure 10. The observed stresses at the midspam of the specimen at $3300 \mathrm{~s}^{-1}$.

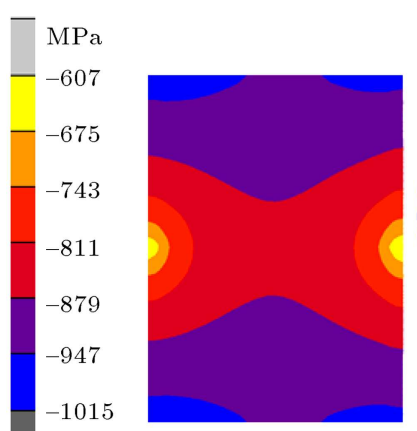

(a)

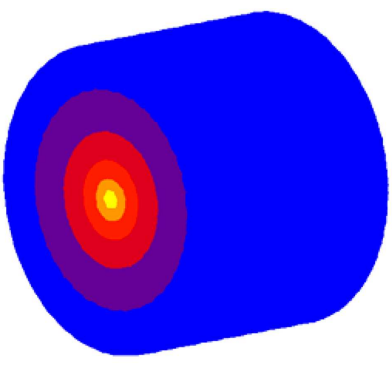

(b)
Figure 11. Axial stress distribution at $t=12 \mu \mathrm{s}$ in (a) sectional-plane and (b) specimen.
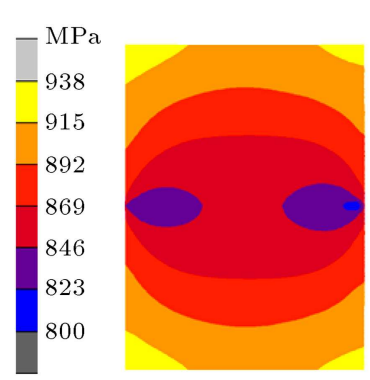

(a)

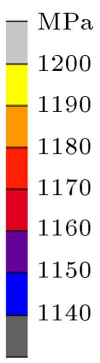

140

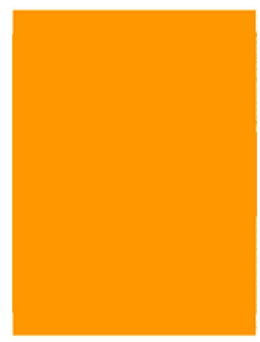

(b)
Figure 12. Equivalent stress distribution in the sectional-plane at (a) $t=12 \mu \mathrm{s}$ and (b) $t=30 \mu \mathrm{s}$ [23].

the variations in equivalent stresses are in the range of approximately $400 \mathrm{MPa}$ and reached homogenous state at $30 \mu \mathrm{s}$, as shown in Figure 12. These results violate the approximation taken in the SHPB tests, stating that the levels of stresses in the axial direction are homogeneous.

Similarly, a non-uniform distribution of temperature was observed at the initial interaction of the incident bar and specimen (see Figure 13). A growth of $117^{\circ} \mathrm{C}$ was observed in the sample due to low

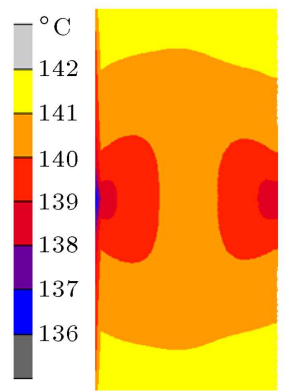

(a)

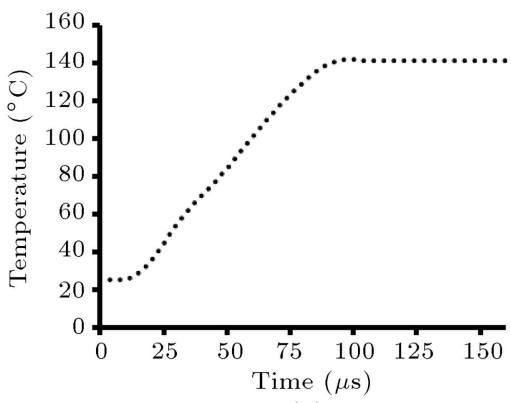

(b)
Figure 13. Temperature distribution and variation with time in the specimen [23].

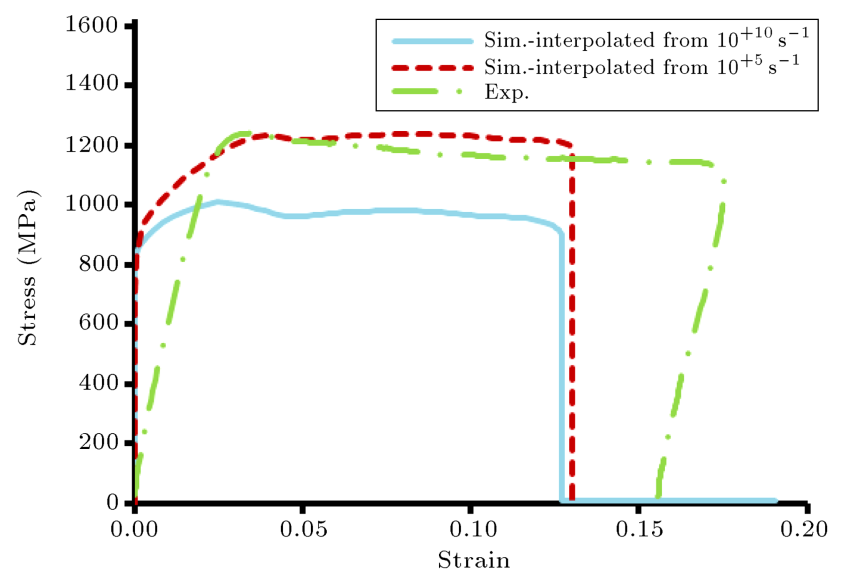

Figure 14. FE and experimental results comparison at $1300 \mathrm{~s}^{-1}$ strain rate.

thermal conductivity of the tested samples, severe plastic deformation, and adiabatic heating conditions.

The developed FE model of SHPB was mainly used to predict the materials' response at high strainrate levels in the current study. The model was simulated to interpolate the materials' response for the known experimentally obtained strain rate levels based on the extrapolated assumed materials' response at higher strain rate. An engineering assumption was used to extrapolate the materials' response at $10^{10} \mathrm{~s}^{-1}$, which is $20 \%$ higher than the measured level of stress-strain response at $3300 \mathrm{~s}^{-1}$. The interpolated material response of the studied material at $3300 \mathrm{~s}^{-1}$ is presented in Figure $14[6,21,22]$. The level of stresses obtained from the FE model was lower than the actual materials' response obtained from SHPB test. The same assumption was also made for the strain rate level of $10^{5} \mathrm{~s}^{-1}$ and reasonably good agreement between the experimental and interpolated FE results was obtained at $1300 \mathrm{~s}^{-1}$ strain rate. The only problem with the achieved FE results was the lower strain level compared to the experimental results; however, to avoid convergence issues caused by the negative slope of materials' response in the FE modelling of UAT and $\mathrm{CT}$, the same level of stress was assumed as a strain 
level of 0.4 . The same approximation was tested at various temperature levels, and the achieved results were in reasonably good agreement with the validated experimental results.

The obtained results of FE model of SHPB setup were used in the FE model of UAT and CT to incorporate materials' response at the strain-rate level of $10^{5} \mathrm{~s}^{-1}$. Although the additional outcomes of inhomogeneity in the stress, strain, and growth in temperature were not incorporated into the current study, a detailed analysis of actual response of materials in SHPB tests was obtained.

\subsection{Analyses of $U A T$ and $C T$ results}

The FE simulations of UAT and CT at various cutting conditions were conducted with the developed FE model and all three-component forces were obtained. In CT of $\beta$-Ti-15333, a magnitude of $110 \mathrm{~N}$ was observed for tangential force components $\left(F_{x}\right)$ at 10 $\mathrm{m} / \mathrm{min}$ speed and $300 \mu \mathrm{m}$ depth of cut. Similarly, the magnitudes of radial force component $\left(F_{y}\right)$ and axial force components $\left(F_{z}\right)$ of $48 \mathrm{~N}$ and $20 \mathrm{~N}$, respectively, were observed (see Figure 15).

The cutting edge was in continuous connection with the workpiece materials after the initial engagement in CT and a uniform level of cutting forces was detected. The small fluctuation in the observed forces is ascribed to the remeshing technique used for chip separation. On the other hand, in UAT, the alternating contact between the cutting insert and the workpiece oscillated the cutting forces between the maximum and minimum levels as presented in Figure 16. The level of cutting forces is almost zero at the approach stage and retraction stage of the cutting insert movement in one complete cycle. The level of cutting forces started to increase at the initial connection between the cutting insert and workpiece during the penetration stage. The level of forces approximately reached the peak force level observed in $\mathrm{CT}$, and then started to decline and

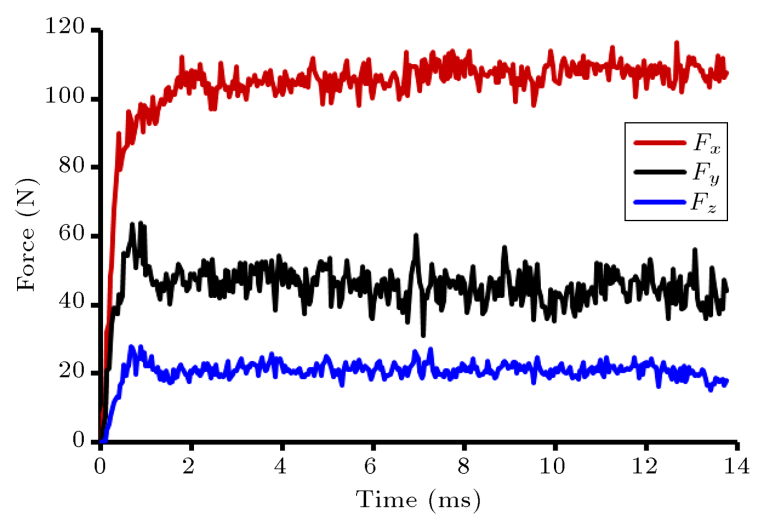

Figure 15. Level of cutting forces calculated in FE simulation of CT at $10 \mathrm{~m} / \mathrm{min}, 300 \mu \mathrm{m}$ depth of cut and $100 \mu \mathrm{m} / \mathrm{rev}$ feed rate.

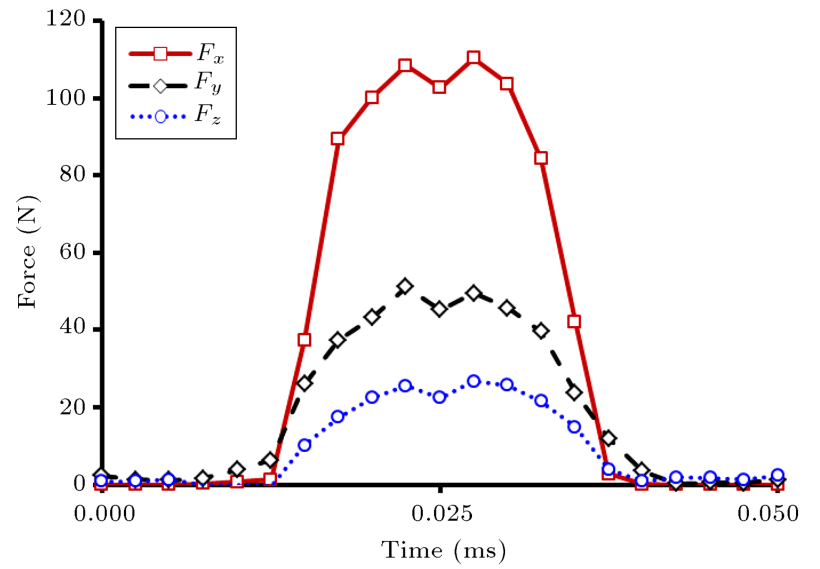

Figure 16. The history of cutting forces in one complete cycle of UAT.

reach zero level when the tool was separated from the chip. Hence, a noteworthy decline in the average level in cutting forces was achieved in UAT compared to CT in the same cutting conditions.

As a result, the average level of $F_{x}$ dropped from $110 \mathrm{~N}$ to $35 \mathrm{~N}$ in UAT. In addition, a considerable decline of $68 \%$ and $55 \%$ in the levels of $F_{y}$ and $F_{z}$ was achieved.

The FE model was used to carry out simulations at the tested depths of cut and a gradual growth in the levels of $F_{x}, F_{y}$, and $F_{z}$ was observed with a growth in the depth of cut in both UAT and CT, as expected. The variation of cutting forces in CT with the depth of cut is presented in Figure 17. The obtained results from the FE model validated the experimental results.

Similarly, the results shown in Figure 18 present the changes in the cutting forces for various depths of cuts in UAT. The depths of cuts varied from $100 \mu \mathrm{m}$ to $500 \mu \mathrm{m}$ and an approximately linear growth in $F_{x}$, $F_{y}$, and $F_{z}$ was noted with it in UAT. The attained simulation results showed excellent agreement with those of the calculated experimental data in UAT. The obtained simulation results in UAT showed an approxi-

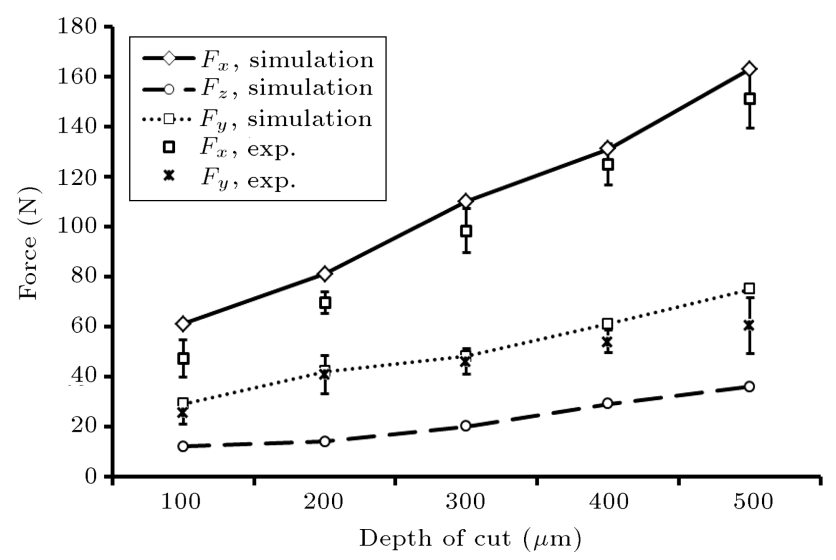

Figure 17. The Level of cutting forces in $\mathrm{CT}$ at various depths of cut. 


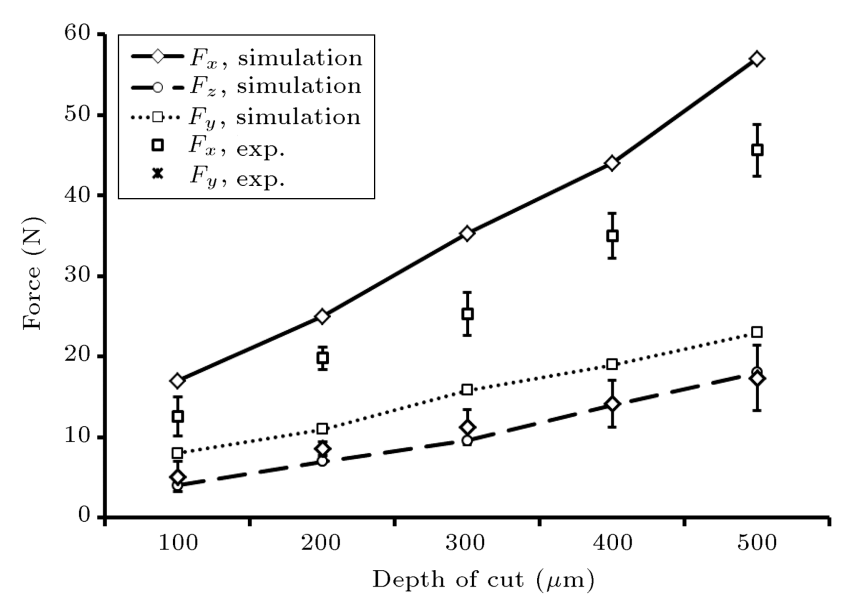

Figure 18. The level of cutting forces in UAT at various depths of cut.

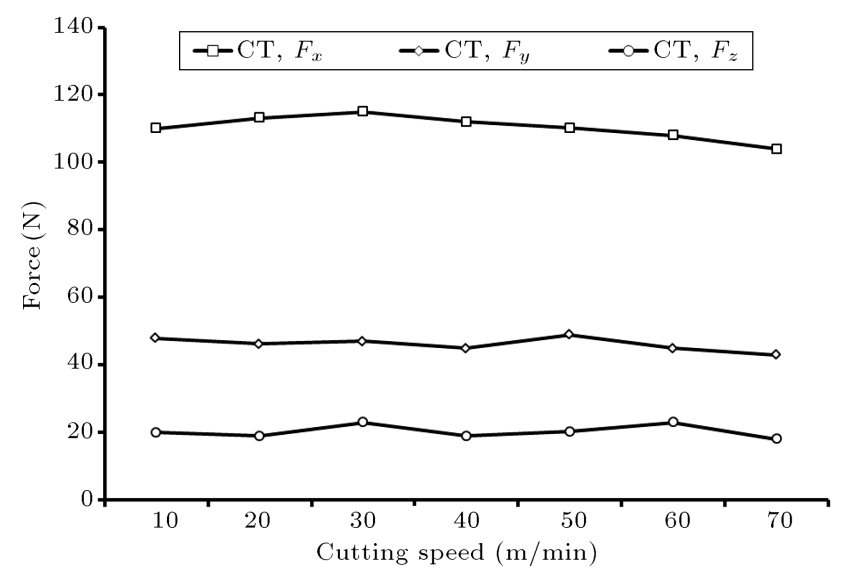

Figure 19. The levels of $F_{x}, F_{y}$ and $F_{z}$ at various cutting speeds in CT.

mately $65-72 \%$ reduction in $F_{x}$. Similarly, a significant reduction of approximately $70 \%$ and $50 \%$ decline in $F_{y}$ and $F_{z}$ was achieved, respectively. The decrease in $F_{x}, F_{y}$, and $F_{z}$ can be ascribed to the separations of insert from the workpiece during retraction stage of tool movement in one complete vibrational cycle as reported. Further analyses showed that the average level of $F_{x}$ in UAT at $500 \mu \mathrm{m}$ is approximately equal to the force levels observed in CT at $100 \mu \mathrm{m}$. Hence, for the equal magnitude of cutting forces, UAT increased the machinability of the studied alloy approximately 5 times when compared to CT.

Furthermore, the effect of cutting speeds going from $10 \mathrm{~m} / \mathrm{min}$ to $70 \mathrm{~m} / \mathrm{min}$ on cutting forces was also analyzed through the developed FE model. Figure 19 presents the cutting forces obtained at the tested speeds in CT. The levels of $F_{x}, F_{y}$, and $F_{z}$ were approximately the same for various cutting speeds. On the other hand, a growth in $F_{x}, F_{y}$, and $F_{z}$ with cutting speeds was observed in UAT and lasted up to $70 \mathrm{~m} / \mathrm{min}$. This growth disappeared beyond $70 \mathrm{~m} / \mathrm{min}$,

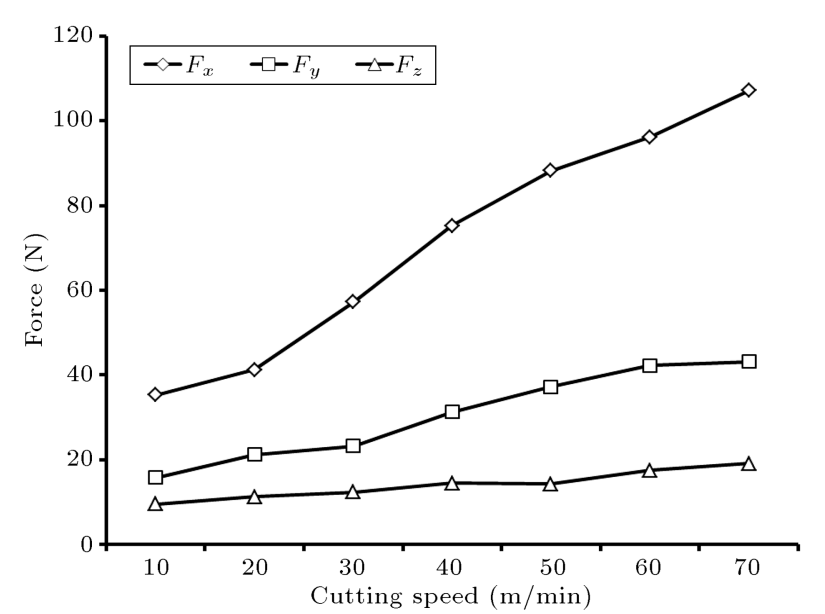

Figure 20. The levels of $F_{x}, F_{y}$ and $F_{z}$ at various cutting speeds in UAT.

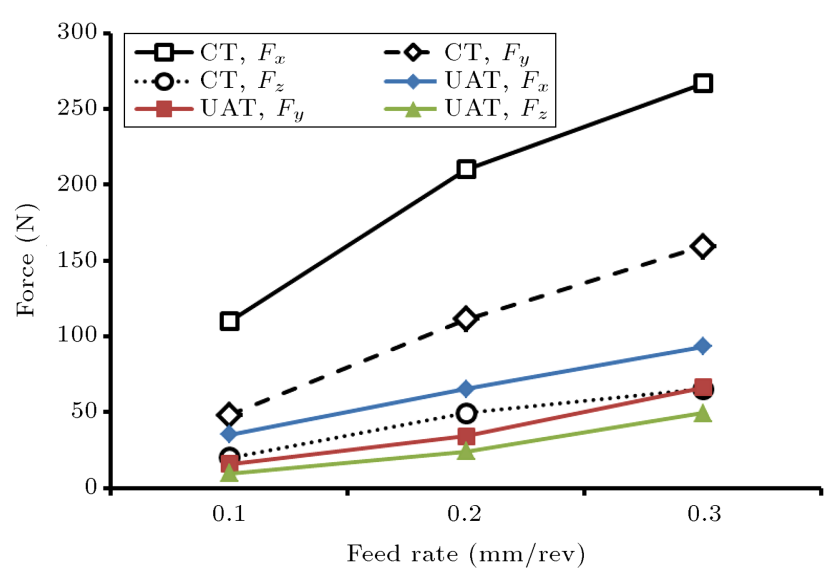

Figure 21. The levels of $F_{x}, F_{y}$ and $F_{z}$ at various feed rates in $\mathrm{CT}$ and UAT.

as the work piece's velocity was high enough to exclude separation between the workpiece and tool in one cycle of ultrasonic vibration (see Figure 20). In UAT, at 60 $\mathrm{m} / \mathrm{min}$ which is the critical velocity of vibrating tool, a drop of approximately $10 \%$ is noted in the level of $F_{x}$ as compared to CT and was ascribed to the thermalsoftening produced in the process zone in UAT due to the process zone temperature. The obtained FE results validated the experimental data presented by Maurotto et al. [20].

The assessment results of the obtained $F_{x}, F_{y}$, and $F_{z}$ at various feed rates in UAT and CT are displayed in Figure 21. A growth in $F_{x}, F_{y}$, and $F_{z}$ was noticed with intensification in feed rate of both turning processes. The quantity of the removed material by the insert at higher feed-rate increases, resulting in higher levels of $F_{x}, F_{y}$, and $F_{z}$ on the insert.

At feed rates of 0.2 and $0.3 \mathrm{~mm} / \mathrm{rev}$, a reduction of approximately $60 \%$ was observed in $F_{x}$ and $F_{y}$ in UAT. However, with an increase in feed rates, the reduction in $F_{z}$ diminished, and $24 \%$ reduction was observed at 


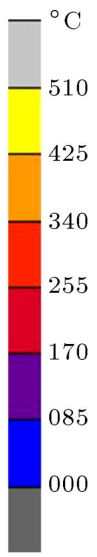

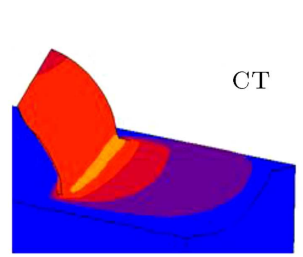

Simulation

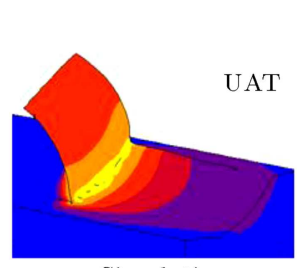

Simulation

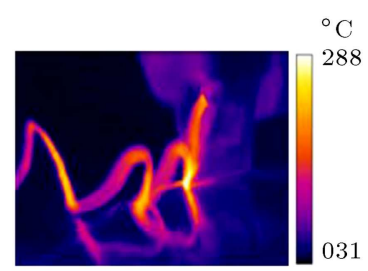

Experimental

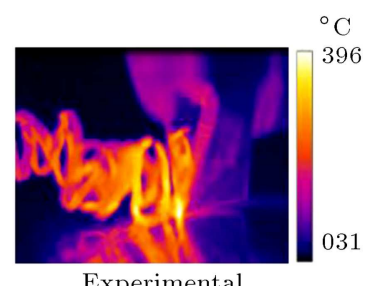

Experimental
Figure 22. Process zone temperature in UAT and CT at $10 \mathrm{~m} / \mathrm{min}, 300 \mu \mathrm{m}$ depth of cut and $100 \mu \mathrm{m} / \mathrm{rev}$ feed rate.

$0.3 \mathrm{~mm} / \mathrm{rev}$. The decline in the drop of $F_{z}$ in UAT is due to a tinier separation of insert at the retraction stage, resulting in a higher average force on the insert. However, the reduction in the levels of $F_{x}$ and $F_{y}$ was noticeable, and hence UAT was also effective at higher levels of feed rate.

The process zone temperature was studied both experimentally and numerically in both UAT and CT, as shown in Figure 22. The observed temperature at the process zone from FE model was slightly higher compared to the level of temperatures observed in experimentations [24,25]. The process zone was obstructed by the chip formed in both UAT and CT, and hence resulted in a lesser assessment of the temperature of the process zone. Still, the temperature level of process zone visible to the line of sight of the infrared camera shows excellent agreement with the acquired FE outcomes. The developed FE model predicts the temperature of those regions, which cannot be investigated with experimentations.

Relatively higher temperature at the process zone of approximately $100^{\circ} \mathrm{C}$ was achieved in UAT both numerically and experimentally. The forced vibration on the insert resulted in a comparatively higher velocity $(60 \mathrm{~m} / \mathrm{min})$ of the cutting edge in the penetration stage; hence, that is responsible for this growth in temperature $[1,3,11,13,15]$.

Similarly, the developed FE model was used for the spreading of von-Mises stress in the studied zone of UAT and CT, as shown in Figure 23. The distribution of stresses was uniform in CT due to the continuous contact of the cutting tool with the workpiece materials. The maximum level of stress observed in the process zone was approximately $1055 \mathrm{MPa}$ in CT. On the other hand, a transient distribution of stresses in the process zone was calculated in UAT due to the intermittent contact of the cutting edge and work piece material. The level of stresses reached approximately

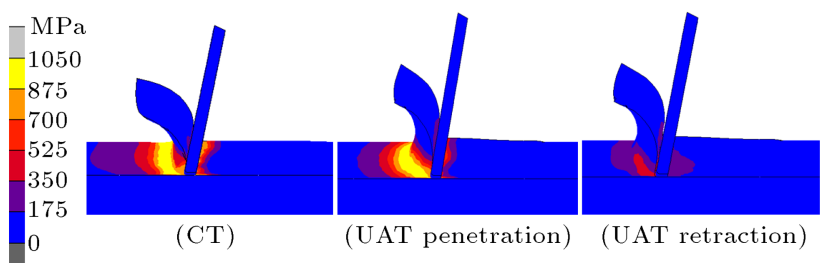

Figure 23. Spreading of von-Mises stress in UAT and CT.

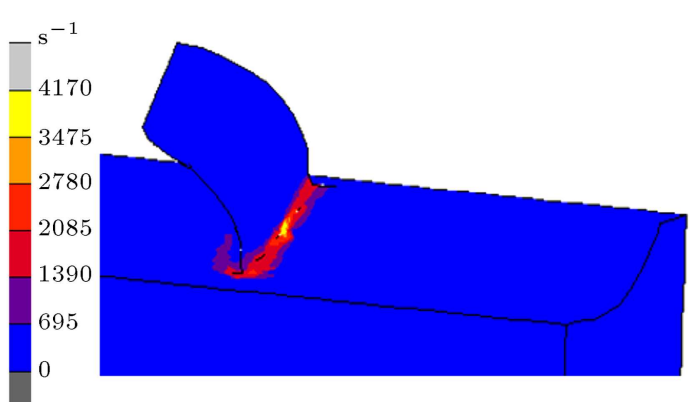

(CT)

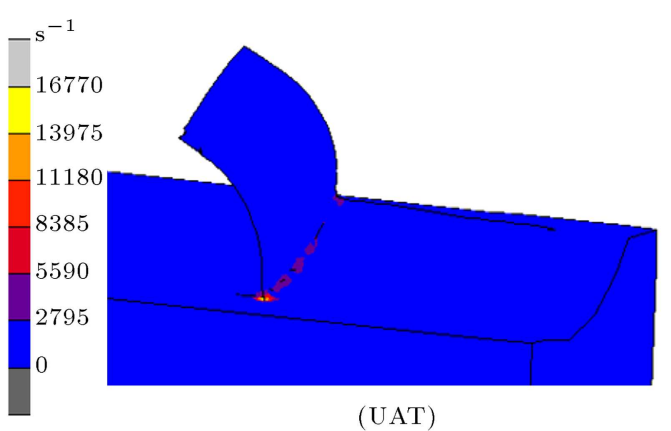

Figure 24. Distribution of strain rate in UAT and CT.

$1050 \mathrm{MPa}$ at the penetration stage and started to decline to the minimum level at the retraction stage when the cutting edge was completely detached from the work piece and chip. The level of average stresses observed in one complete cycle of UAT is significantly lower compared to the level of stresses observed in CT. However, the level of stress reached the level observed in $\mathrm{CT}$ for a fraction of time during the penetration stage.

Furthermore, the FE model was also used to predict the level of strain rate induced in UAT and CT of Ti-15333, as displayed in Figure 24. The level of strain rate calculated at the penetration stage in UAT was considerably higher than that observed in CT. The vibration supplied to the cutting tool resulted in transient contact with the workpiece material, and hence resulted in a four-time increase in the level of strain rate in UAT.

\section{Conclusion}

The FE model was developed for SHPB setup to investigate the behaviour of Ti-15333 at various strain-rate, 
strain, and temperature. The developed model was validated by the available experimental data. The model was used to predict Ti-15333 behaviour at the elevated strain rate of $10^{5} \mathrm{~s}^{-1}$. The deformation behaviour was inhomogeneous for Ti-15333 at the initial stages of compression in SHPB simulations, contradicting the main assumption made for stress-strain response calculation of the SHPB tests. Similarly, a growth in temperature of the specimen due to adiabatic heating condition was also observed. These observations should be taken into consideration for future calculation of Ti15333 materials model's parameters.

The obtained materials' response of Ti-15333 at higher strain from the SHPB simulation was used in the thermos-mechanically coupled FE model of UAT and CT. The developed model has an added advantage of predicting $F_{x}, F_{y}$, and $F_{z}$ in both UAT and CT. A significant drop of approximately $70 \%$ in the level of $F_{x}$ was observed. The model is also capable of explaining the reduction in the level of $F_{y}$ and $F_{z}$ in UAT. The FE results show that UAT is effective in both higher feed rates and depth of cuts, resulting in a significant drop in all the three components of forces. The observed temperature at the process zone is relatively high in UAT. The predicted FE results are in good agreement with the validated experimental results.

\section{Acknowledgements}

This research work was carried out under the grant of MaMiNa project, supported by EU 7th-Framework Program, agreement number: PITN-GA-2008-211536.

\section{References}

1. Muhammad, R., Hussain, M.S., Maurotto, A., Siemers, C., Roy, A. and Silberschmidt, V. "Analysis of free machining of $\alpha+\beta$ Ti-alloy using conventional and ultrasonically assisted turning", J. of Mater. Proc. Tech., 214(4), pp. 906-915 (2014).

2. Maurotto, A., Siemers, C., Muhammad, R., Roy, A. and Silberschmidt, V. "Ti alloy with enhanced machinability in UAT turning", Metall. and Mater. Trans. A., 45(6), pp. 2768-2775 (2014).

3. Muhammad, R., Roy, A. and Silberschmidt, V.V. "Finite element modelling of conventional and hybrid oblique turning processes of titanium alloy", Proc. CIRP., 8, pp. 509-514 (2013).

4. Muhammad, R. "Hot ultrasonically assisted turning of Ti-15V3Al3Cr3Sn: experimental and numerical analysis", Wolfson School of Mechanical and Manufacturing Engineering, PhD (2013)

5. Muhammad, R., Maurotto, A., Demiral, M., Roy, A. and Silberschmidt, V. "Thermally enhanced ultrasonically assisted machining of Ti alloy", CIRP J. of Manuf. Sci. and Tech., 7(2), pp. 159-167 (2014).
6. Muhammad, R., Ahmed, N., Roy, A. and Silberschmidt, V.V. "Numerical modelling of vibrationassisted turning of Ti-15333", Proc. CIRP., 1, pp. 347352 (2012).

7. Zhao, H. and Gary, G. "On the use of SHPB techniques to determine the dynamic behavior of materials in the range of small strains", Int. J. of Sol. and Struct., 33(23), pp. 3363-3375 (1996).

8. Bell, J.F. "An experimental diffraction grating study of the quasi-static hypothesis of the split Hopkinson bar experiment", J. of the Mech. and Phy. of Solid, 14(6), pp. 309-327 (1966).

9. Davies, E.D.H. and Hunter, S.C. "The dynamic compression testing of solids by the method of the split Hopkinson pressure bar", J. of the Mech. and Phy. of Solid, 11(3), pp. 155-179 (1963).

10. Yang, L.M. and Shim, V.P.W. "An analysis of stress uniformity in split Hopkinson bar test specimens", Int. J. of Imp. Engg., 31(2), pp. 129-150 (2005).

11. Muhammad, R., Demiral, M., Roy, A. and Silberschmidt, V.V. "Modelling the dynamic behaviour of hard-to-cut alloys under conditions of vibro-impact cutting", J. of Phy.: Conf. Ser., 451, pp. 1-8 (2013).

12. Johnson, G.R. and Cook, W.H. "Fracture characteristics of three metals subjected to various strains, strain rates, temperatures and pressures", Engg. Fract. Mech., 21(1), pp. 31-48 (1985).

13. Muhammad, R., Maurotto, A., Roy, A, and Silberschmidt, V.V. "Ultrasonically assisted turning of Ti6Al-2Sn-4Zr-6Mo", J. of Phy.: Conf. Ser., 382 (2012).

14. Muhammad, R., Ahmed, N., Shariff, Y.M. and Silberschmidt, V.V. "Finite-element analysis of forces in drilling of Ti-alloys at elevated temperature", Solid State Phenom., 188, pp. 250-255 (2012).

15. Muhammad, R., Ahmed, N., Roy, A. and Silberschmidt, V.V. "Turning of advanced alloys with vibrating cutting tool", Solid State Phenom, 188, pp. 277-284 (2012).

16. Muhammad, R., Ahmed, N., Abid, M. and Silberschmidt, V.V. "3D modeling of drilling process of AISI 1010 steel", J. of Mach. and Form. Tech., 2(3/4), pp. 201-216 (2010).

17. Calamaz, M., Coupard, D. and Girot, F. "A new material model for 2D numerical simulation of serrated chip formation when machining titanium alloy Ti-6Al4V", Int. J. of Mach. Tools and Manuf., 48(3-4), pp. 275-288 (2008).

18. Li, Z. and Lambros, J. "Determination of the dynamic response of brittle composites by the use of the split Hopkinson pressure bar", Comp. Sci. and Tech., 59(7), pp. 1097-1107 (1999).

19. Hokka, M., Leemet, T., Shrot, A., Bäker, M. and Kuokkala, V.-T. "Dynamic behavior and numerical 
modeling of titanium 15-3-3-3 alloy", in Dynamic Behavior of Materials, V. Chalivendra, Song, B. and Casem, D., Eds., Springer, New York, 1, pp. 235-242 (2013).

20. Maurotto, A., Muhammad, R., Roy, A. and Silberschmidt, V.V. "Enhanced ultrasonically assisted turning of a $\beta$-titanium alloy", Ultrasonics, 53(7), pp. 1242-1250 (2013).

21. Shi, Q., Tse, Y.Y., Muhammad, R., Roy, A., Silberschmidt, V.V. and Higginson, R.L. "Effect of machining on shear-zone microstructure in Ti-15V-3Cr-3Al3Sn: conventional and ultrasonically assisted turning", J. of Mat. Engg. and Perform., 25(9), pp. 3766-3773 (2016).

22. Muhammad, R., Demiral, M., Ahmed, N., Roy, A., and Silberschmidt, V.V. "Computational study of ultrasonically-assisted turning of Ti alloys", Adv. Mater. Res., 223, pp. 30-36 (2011).

23. Muhammad, R., Demiral, M., Roy, A. and Silberschmidt, V.V. "Modelling the dynamic behaviour of hard-to-cut alloys under conditions of vibro-impact cutting", J. of Phy.: Conf. Ser., 451, pp. 1-11 (2013).

24. Muhammad, R., Maurotto, A., Roy, A. and Silberschmidt, V.V. "Analysis of forces in vibro-impact and hot vibro-impact turning of advanced alloys", App. Mech. and Mat., 70, pp. 315-320 (2011)

25. Muhammad, R., Mistry, A., Khan, S.W., Ahmed, N., Roy, A. and Silberschmidt, V.V. "Analysis of tool wear in ultrasonically assisted turning of $\beta$-Ti-15V-3Al-3Cr3Sn alloy", Scientia Iranica, Transac. B: Mech. Engg., 23(4), pp. $1800-1810$ (2016).

\section{Biographies}

Riaz Muhammad graduated in Mechanical Engineering with distinction from UET Peshawar, Pakistan in 2006 followed by his Master and $\mathrm{PhD}$ degrees in Mechanical Engineering from Ghulam Ishaq Khan Institute of Science and Technology (GIKI) and Loughborough University in 2009 and 2013, respectively. $\mathrm{He}$ is currently working as an Associate Professor in the Department of Mechanical Engineering, CECOS University of IT and Emerging Sciences, Pakistan. His research activities include finite-element modelling, hybrid machining process, composite, polymers and biomedical materials.

Naseer Ahmed received BS and MS degrees in Mechanical Engineering from UET Peshawar and GIKI, respectively. He received his $\mathrm{PhD}$ degree form Loughborough University, UK, in 2007. He is a Professor of Manufacturing at CECOS University, Pakistan, and heads the Mechanics of Advanced Materials and Manufacturing Research Group (AM2RG) and the Director of research and development. His research activities include manufacturing, biomedical materials, composite materials, and assisted machining processes.

Himayat Ullah received his BS in Mechanical Engineering from UET Peshawar, Pakistan in 1998. He received his $\mathrm{PhD}$ degree from Loughborough University, UK, in 2013, in composite and advanced materials. His research interest includes FE simulation, machining, composite materials, computational mechanics, and mechanics of materials.

Vadim V. Silberschmidt was educated at Perm Technical University (USSR). He heads the Mechanics of Advanced Materials Research Group with $30+$ members. He is a Charted Engineer, Fellow of the Institution of Mechanical Engineering and Institute of Physics. He is Editor-in-Chief of Mechanics of Advanced Materials and Modern Processes, Associate Editor of Journal of Engineering Materials and Technology. His research activities include multi-scale models of damage and fracture evolution in microstructured materials, finite-element analysis of complex deformational behaviour, damage and fracture of advanced materials under various loading conditions, impact fatigue, mechanics of composites and nano-composites, mechanics. 